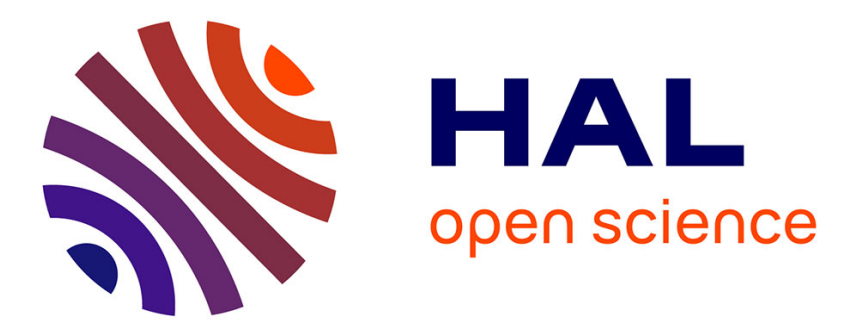

\title{
How to Implement Computing Education for All - Discussion of Alternative Organisational Models
}

Torsten Brinda

\section{To cite this version:}

Torsten Brinda. How to Implement Computing Education for All - Discussion of Alternative Organisational Models. 11th IFIP World Conference on Computers in Education (WCCE), Jul 2017, Dublin, Ireland. pp.648-652, 10.1007/978-3-319-74310-3_65 . hal-01762860

\section{HAL Id: hal-01762860 \\ https://hal.inria.fr/hal-01762860}

Submitted on 10 Apr 2018

HAL is a multi-disciplinary open access archive for the deposit and dissemination of scientific research documents, whether they are published or not. The documents may come from teaching and research institutions in France or abroad, or from public or private research centers.
L'archive ouverte pluridisciplinaire HAL, est destinée au dépôt et à la diffusion de documents scientifiques de niveau recherche, publiés ou non, émanant des établissements d'enseignement et de recherche français ou étrangers, des laboratoires publics ou privés. 


\title{
How to Implement Computing Education for All - Discussion of Alternative Organisational Models
}

\author{
Torsten Brinda \\ University of Duisburg-Essen, Computing Education Research Group, Germany \\ torsten.brinda@uni-due.de
}

\begin{abstract}
In the context of the implementation of computing education for all school students, different implementation models are proposed and discussed: integration of computer science concepts and competencies into existing school subjects, establishment of a separate computing subject, offers of workshops and projects in schools, and out-of-school activities. Within the context of this position paper, the afore-mentioned implementation variants are discussed and evaluated.
\end{abstract}

Keywords: Computing Education, Integration, Mandatory Subject.

\section{Introduction}

The progressive imprinting of our life- and work environments by means of digitalization and the resulting, pressing challenges of personal, social and economic nature make it necessary for educational policy to respond to these challenges by further development of school education. It is noteworthy that the choice of compulsory school subjects in most countries remained essentially unchanged since the time before digitalization. Students learn several languages in order to be able to read and to write and to be prepared for the challenges of increasing internationalization. They deal with mathematics in order to understand and calculate quantitative facts. They get to know the aesthetics of musical and artistic artefacts to understand them and to discover and develop a potential talent in this area. The same applies to the social and natural sciences. Personal insights concerning interest or even talent are also possible because pupils have to take - to a certain extent compulsory components in these areas and thus are led to processes of understanding, analysis and creation in the particular subject. With regard to aspects concerning the world characterized by digitalization, often only electoral offers (optional subjects, working groups, etc.) are provided and it is thereby left to the self-responsibility of the pupils to ascertain themselves whether they would be interested and could be successful in this field. In view of the challenges faced by digitalization, it is necessary that all pupils become adequately computing-literate in order to also understand this part of the world surrounding them and to be prepared for active participation to extend comparable to other subjects [1]. There are different approaches to implementing computing education for school students, which are discussed in the following section. 


\section{Discussion of Organizational Models of Computing Education}

\subsection{Integration into Existing Subjects}

There are a number of questions concerning the integration of new learning objectives into existing school subjects while leaving the available teaching time unchanged. The teachers of the respective subjects must be prepared to integrate computing competencies or have to be motivatable in an extrinsic manner. Furthermore, they must be able to acquire the necessary competencies by themselves or with the help of others to such an extent that they can competently prepare and give own lessons. Large-scale international studies on the integration of digital media into school subjects showed that this approach has not been successful in the past (e. g. [2]). It is thus left to chance in the respective field, which competencies the learners will acquire, which is problematic with regard to ensuring equal opportunities for all of them. The binding nature of competencies could be increased by using the outcomerelated control mechanisms of the respective school administration (e. g. educational standards, centralized learning-level surveys, centralized exams). This could help counteract unfavorable developments. Since the individual school is usually only reached every several years by central learning surveys, demonstrable changes - even against the will of individual teachers - are, however, a lengthy process. In the case of integration into other subjects, media and computing competencies would then have to be assessed in this way, school-internal curricula including these competencies would have to be designed and maintained for standardization. What has apparently already been a challenge for the use of digital media, which was not mastered successfully in a broad way, should be almost hopeless in the case of computing concepts despite the possible inclusion of output control. While the integration of digital media requires "only" their intelligible and didactically reflected application from the particular subject perspective and "only" is an extension of the tools available for teaching certain competencies, it is still about teaching and learning in the respective subject. An inclusion of computer science concepts requires a completely new, unfamiliar perspective. This is not to deny that a large number of teachers of other subjects are already including computing concepts and competencies in their respective subjects or support extracurricular offers. This is generally positive, provided that it is done in a technically competent way, but it is essentially determined by the motivation, the specific qualifications and the commitment of these persons and it may be more than doubted that a large number of teachers of other subjects would develop enough enthusiasm for that, especially in the light of the fact that they have deliberately opted for their respective subjects. Furthermore, no systematic statement can be made about the computing qualification of these teachers and the extent to which the objectives of computing education are pursued and achieved.

In order to obtain an adequate view of computer science, teacher education study programmes in Germany require passing modules taken from the fields of programming, algorithms and data structures, modelling, software engineering, databases, computer networks, operating systems, computer architecture, formal languages and automata, impacts of computing, and computing education [3] - in short, a complete computer science teaching degree study, which would have to be 
studied as an additional subject. A reduced selection of individual modules, however, only reveals individual aspects; the underlying principles and the design of computing systems, their impacts on society and the teaching of corresponding concepts are only revealed in the completeness. The inclusion of new competencies in an existing subject with the same time for instruction also inevitably raises the question of what other content should be reduced. While the inclusion of digital media would only lead to a different media-based teaching-learning process, the inclusion of computing competencies (as described in curricular recommendations, e.g. k12cs.org) would in fact necessarily lead to the analysis of which of the host-subject's concepts and competencies should be reduced. In this respect the same question arises here, which also needs to be answered in the case of a mandatory subject.

\subsection{A Separate (Mandatory) Subject for Computing Education}

According to Fluck et al. [4] the reasons for a (mandatory) computing subject are essentially social, cultural and economic. From a social point of view, it is desirable to enable young people to participate actively in society also from a technological perspective and not only to turn them into passive consumers of technology. This also includes recognizing and promoting the new technical possibilities with regard to their potential to increase productivity. Media and tools have often served as enhancers of human skills (see [5, p. 6-8]). A hammer reinforces the possibilities of the hand, a vehicle that of the legs, through texts arise new possibilities of selfexpression and thought. In future, many people will get into contact with programming in their private lives as well as in their jobs and even program to a certain extent - but without being or becoming a software developer. The aim of "learning to program" is not to enable everybody to program systems such as MS Office or Facebook, as "learning to write" does not necessarily lead to writing an 800page world bestseller book in the future - but it is a prerequisite. Computing-literate people can express themselves more comprehensively, that is also by means of computer science, and thus obtain further possibilities for action, which contributes to an increase in their productivity potential. On the other hand, uninformed decisions lead to social costs through lost productivity. All those who are qualified can, as wellinformed citizens, decide by themselves which role they want to take in society from user to creator everything is possible. From a cultural perspective, it is about empowering people to actively co-shape cultural change and not simply accept it as given and to adapt their lives accordingly. From an economic point of view, there is a great demand for specialists in the ICT sector both in Germany and abroad. In order to make and keep the respective country internationally competitive in a world increasingly characterized by computer science (see [4]), it is necessary to open up young people more than previously also professional career paths in this area. This requires that more pupils acquire competencies in the field of computer science, learn about the discipline in analogy to others represented in the school and can develop self-confidence and interest in it. The international perspective shows that computing competencies are becoming mandatory in more and more countries (e. g. [1]).

Furthermore, a separate subject offers the possibility to systematize, structure and network the technical concepts by placing them in an overall picture. Teachers, who have not studied computer science as a subject, cannot take responsibility for this, because, even if they have received a basic qualification in computer science, they can 
only have a very limited view of the discipline. In this context, a comparison with the school subject related to mother tongue, e.g. German language, is helpful. German language is used in all except for foreign language classes in Germany. Nevertheless, in German classes, the language itself is not only analysed, but also artefacts are produced in order to be not only a "consumer", but also a "creator" (i.e. a writer) of German language artefacts oneself. In order to promote reading in an understanding way, lessons deal, for example, with syntactical and grammatical aspects and examine the structure and special characteristics of typical text categories (e.g. authors' intentions). Furthermore, texts of different categories are produced (e.g. essays, discussions, definitions). This results in a stepwise construction of the systematics in the subject German combined with a domain-specific application of German language in (almost) all other subjects. This analogy can be well applied to the argument here. Working with digital media in other subjects also provides specific links to computer science, e.g. the functioning of semiconductors in physics, audio compression processes in music. A computing subject builds a systematic structure analogously to the language subject above, and can thus integrate cross-references to subject-specific aspects in an overall picture. This promotes the development of corresponding knowledge structures of the learners. The host-subjects' teaching staff, who have not studied computer science, cannot take responsibility for this, because they lack the necessary disciplinary overview of computer science. In this respect, both the integration and a separate subject are required.

Against an elective subject it is argued that their offering and choice are strongly dependent on local contexts and discussions taking place in them. By means of optional respectively optional compulsory subjects, continuous work and systematic competence development is not possible for all pupils.

\subsection{School working groups/projects}

Working groups or projects enable pupils to pursue individual interests and to deepen themselves in these areas. This is fundamentally welcome and a valuable tool for the design of learning processes at school. However, this approach is unsuitable for developing competencies, which all students of a generation should develop in the same quality, since the prerequisite would be a gapless offer of corresponding working groups or projects and the competency acquisition would have to be systematically enabled and assessed. This would be the same as a mandatory school subject.

\subsection{Out-of-school activities}

Outreach activities of various kinds enable pupils to get to know selected ideas of computer science in temporary workshops. Due to the time constraints and the locally different availability of such offers, neither a systematic competency development nor equality of opportunity can be achieved for all learners. 


\section{Conclusions}

Since educational policy sometimes seems to avoid to answer the question, where the required lesson time for a new mandatory subject should come from, the concepts and competencies of this field are often either abstractly delegated for integration into all or a choice of other subjects, or totally discarded. In the case of teaching and learning with digital media in all subjects, broad integration was not yet successful, so it seems even less achievable in the case of computer science concepts and competencies. Furthermore, the goal of integrating computer science in all subjects leads to a deprofessionalization of the profession of computing teachers, since it could then be concluded that every teacher can and would like to take over the respective tasks in addition to his or her own ones and that no particular study is needed for that. This can only lead to either no systematic computing education at all, or one only at a professional level, which can be supported by a large number of teachers - it would be surprising, if this level would exceed that of primary education significantly. Since the recruitment of teachers is essentially controlled by school subjects, a separate mandatory computing subject seems to be without alternative at the present time.

To this end, all countries should develop a plan for the computing competencies that all learners should acquire in the future, and by which time this should be implemented in which way in the school system.

\section{References}

1. Hubwieser, P., Giannakos, M. N., Berges, M., Brinda, T., Diethelm, I., Magenheim, J., Pal, Y., Jackova, J., Jasute, E.: A Global Snapshot of Computer Science Education in K12 Schools. Proceedings of the 2015 ITiCSE on Working Group Reports (ITICSE-WGR '15). ACM, New York, 65-83, http://dx.doi.org/10.1145/2858796.2858799 (2015).

2. $\quad$ Plomp, T., Anderson, R.E., Law, N.; Quale, A. (eds.): Cross-National Information and Communication Technology: Policies and Practices in Education. Information Age Publishing, Charlotte, USA (2009).

3. Secretary of the Standing Conference of the Ministers of Education and Cultural Affairs of the Federal Countries of Germany (ed): Ländergemeinsame inhaltliche Anforderungen für die Fachwissenschaften und Fachdidaktiken in der Lehrerbildung. Beschluss der Kultusministerkonferenz vom 16.10.2008 i. d. F. vom 06.10.2016 (in German), http://www.kmk.org/

fileadmin/Dateien/veroeffentlichungen_beschluesse/2008/2008_10_16-FachprofileLehrerbildung.pdf (2016).

4. Fluck, A., Webb, M., Cox, M., Angeli, C., Malyn-Smith, J., Voogt, J.; Zagami, J.: Arguing for Computer Science in the School Curriculum. Journal of Educational Technology \& Society, 19(3), 38-46 (2016).

5. Guzdial, M.: Learner-Centered Design of Computing Education: Research on Computing for Everyone. Synthesis Lectures on Human-Centered Informatics 8(6), 1-165 (2015). 